\title{
Analysis and Detection of Seepage Path of Nanmenxia Reservoir Using Ground Penetrating Radar
}

\author{
YUAN Baoyuan ${ }^{1, a^{*}}$, GENG Changliang ${ }^{1, b}$ and BAI Yun ${ }^{2, c}$ \\ ${ }^{1}$ College of Earth Science and Engineering, Hohai University, Nanjing, China \\ ${ }^{2}$ Water Conservancy and Hydropower Survey and Design Institute of Qinghai, Xining, China \\ ayuanby1967@sina.com, b1148564652@qq.com, qhslby219715@163.com
}

Keywords: Ground Penetrating Radar, Nanmenxia Reservoir, seepage path, detection and analysis Abstract. Nanmenxia Reservoir has a significant benefit. Due to the complex geological conditions, the reservoir leakage was serious. The effect of previous anti-seepage treatment was not obvious. Finding out the leakage location and path of anti-seepage treatment was very important. Through the introduction of British Groundvue series of Ground Penetrating Radar System, the seepage channel was detected, and main leakage paths of the reservoir were looked for. By detecting drawed a conclusion that there was obvious strong leakage band in the bedrock, the previous curtain grouting belt and dam foundation seepage cut-off wall has $3 \mathrm{~m}$ in horizontal derechtion, the local obviously broken belt developed on the right bank of the grouting trnnel. It provided technical support for design and construction of danger removal and reinforcement for Nanmenxia Reservoir.

\section{Introduction}

Nanmenxi reservoir is a medium-sized project mainly used for irrigation. It was founded in 1974 and put into operation in 1982 . Because the reservoir is located in karsts areas, it has complex geological conditions, the structure karsts and fracture of dam base and two dam abutment was very development. Leakage is also serious. Seepage treatment works of Nanmenxia reservoir have already begun as early as 1975 during the dam construction. It has been carried out three stages of curtain grouting, but the effect was not ideal. Sectional view of Nanmenxia reservoir dam was shown in Figure 1.

The geographical location of Nanmenxia Reservoir's is important. It's operational efficiency is significant, but it's karsts seepage was serious, so its reinforcement is readied to carry out. Because of complex geological conditions, karsts and fracture was unknown. Previous anti-seepage treatment effect was not obvious, it was urgent need to identify the location and path of karsts leakage.

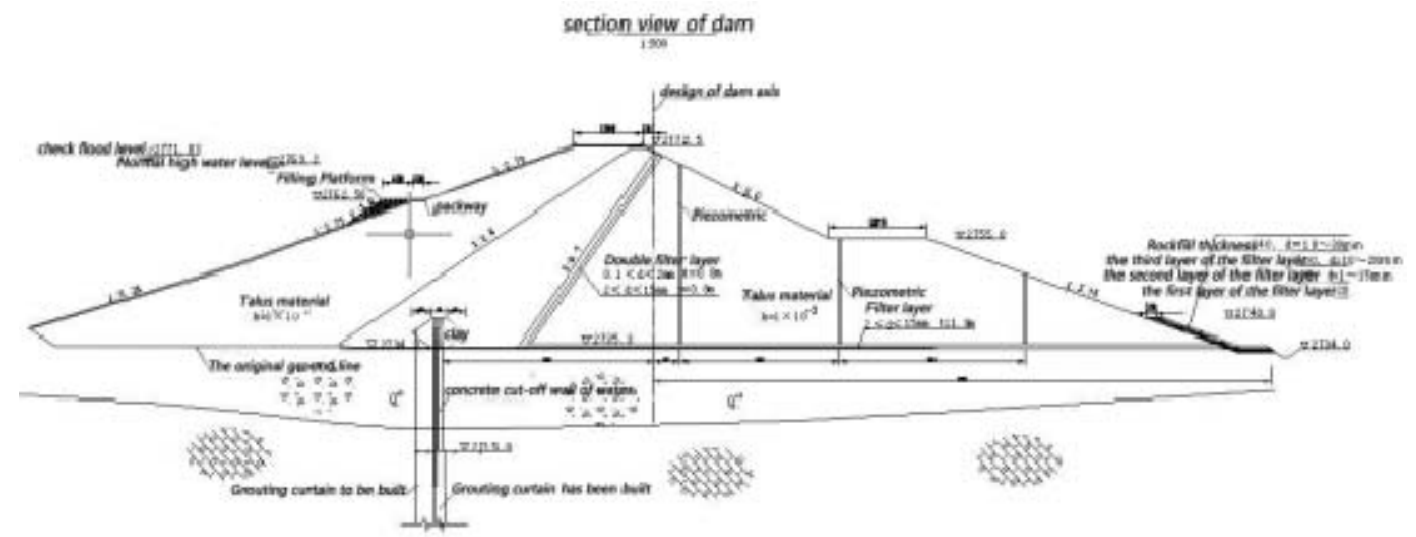

Figure 1 Sectional view of Nanmenxia reservoir dam

By introduction of GPR equipment and technology, combined with on-site testing and validation, to confirm Nanmenxia reservoir leakage path and distribution, which is necessary to provide technical support for the reinforcement construction. 


\section{Test method}

To solve the leakage path problem in the reinforcement process of Nanmenxia reservoir, the advanced British Groundvue series of Ground Penetrating Radar instrument was adopted for field testing.

Groundvue radar was invented by famous radar expert Vincent Utsi and his team of British Utsi Electronics Company. In order to feet the requirements of measurement on the depth and the accuracy, GV2 and GV6 were used to probe the dam crest, the dam's before and after slop of Nanmenxia reservoir.

The principle of continuous profile scanning detection was shown in figure 2. In the actual detection, the continuous profile scanning detection has the following features: the transmitting antenna (T) and receiving antenna (R) move forward at the same time along the survey line with a certain distance between them, so as to detect the underground object. The $\mathrm{T}$ and $\mathrm{R}$ of ground penetrating radar, when passing the survey points, will record the next echo waveform. As a result, when radar finalizes the detection task along the survey line, it has gained the ground penetrating radar echo waveform graph of underground objects on the position of survey line.

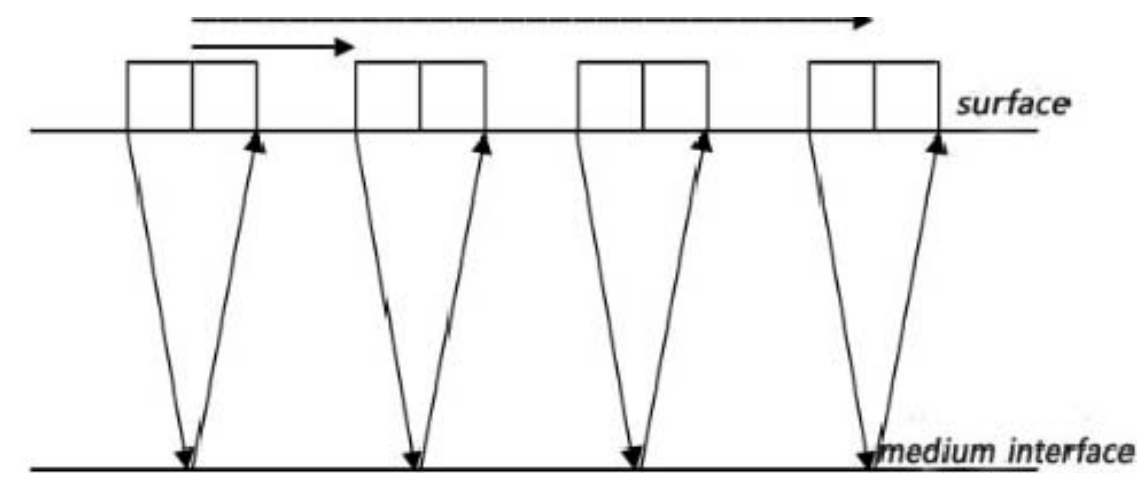

Figure 2 GPR reflection method detection diagram

The abscissa is the ground surface position of apparatus when making measurement, which is the coordinate of test points. The ordinate is the two-way time in which the electromagnetic wave is from transmits to receive by the ground penetrating radar. When detecting actually and recording data, we can record multiple data continuously and adopt average processing method to reduce the random error produced in the survey. Such recording means does not need to make re-handling of eco waveforms and can directly reflect the features of underground reflecting interfaces on the position of survey line.

\section{Test feedback}

Through systematic on-site test and data analysis of GV GPR, some valid conclusions relating to the reservoir reinforcement have been obtained, and some of the conclusions have been well verified by drilling. The main results were following aspects:

Fractured zones at grouting tunnel on the right bank. Through GV2 GPR test and analysis in the right bank of the dam grouting tunnel, the test results showed that the $0+450$ to $0+470 \mathrm{~m}$ section of right bank of the grouting tunnel exists obvious fractured zones, as shown in Figure 3. it need to be paid full attention in reinforcing.

Conditions of the seepage cutoff wall of dam foundation. It is between base surface and the bedrock surface, used to prevent gravel overburden on the bedrock surface seep. Due to the lack of accurate drawings of the original design, during the previous dam foundation grouting, it was generally believed that the cut-off wall was on the edge of the existing grouting platform and paralleled with the strike of the dam. By GV6 GPR test in dam fore slope in the direction of survey line is perpendicular to the dam axis, we found the seepage cut-off wall is vertical to dam axis in the horizontal direction, $2 \sim 3 \mathrm{~m}$ away from the existing grouting platform, as shown in Figure 4 . This may be an important reason of previous poor grouting effect. 
Many cross-sectional interpretation of GPR test results which is vertical to the dam axis show the cut-off wall of dam foundation continue good and keep straight in between $40 \sim 0+0+380$. The drilling work of five section on site verified the results of GPR.

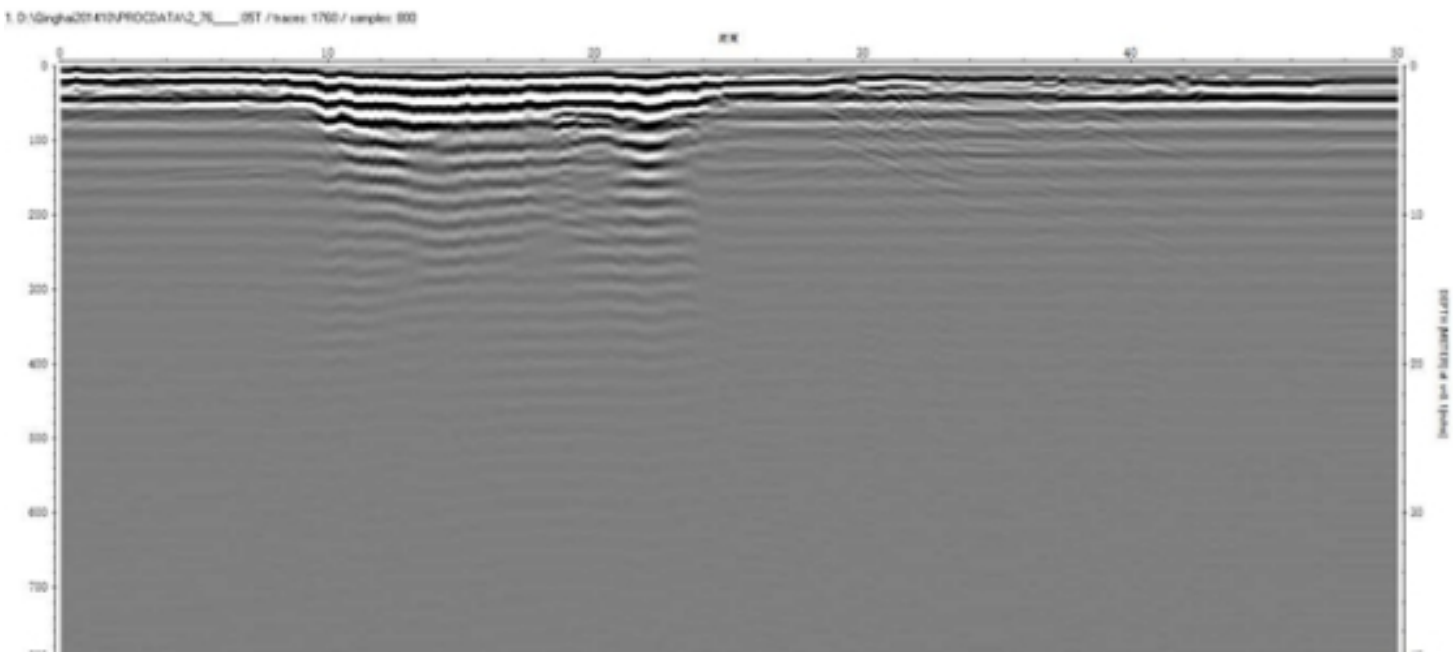

Figure 3 GV2 GPR gray scale of grouting adit on the right bank

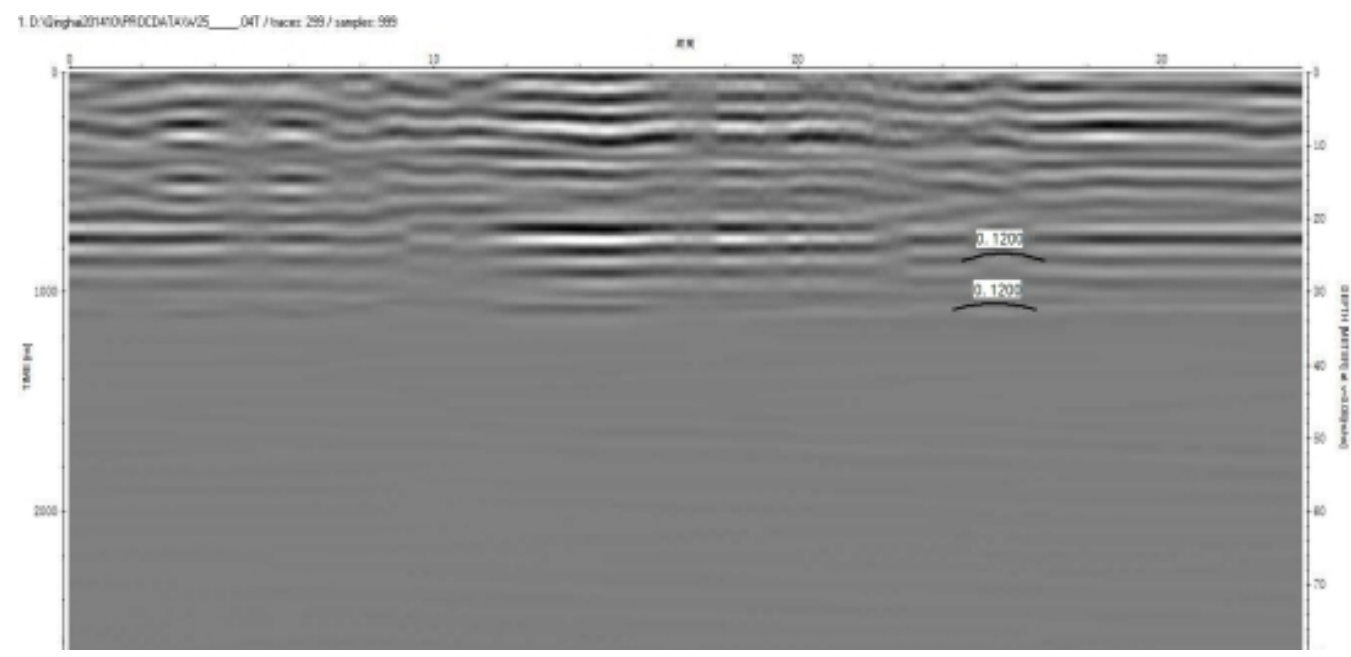

Figure 4 GV6 GPR gray scale in front slope of dam vertical to dam axis

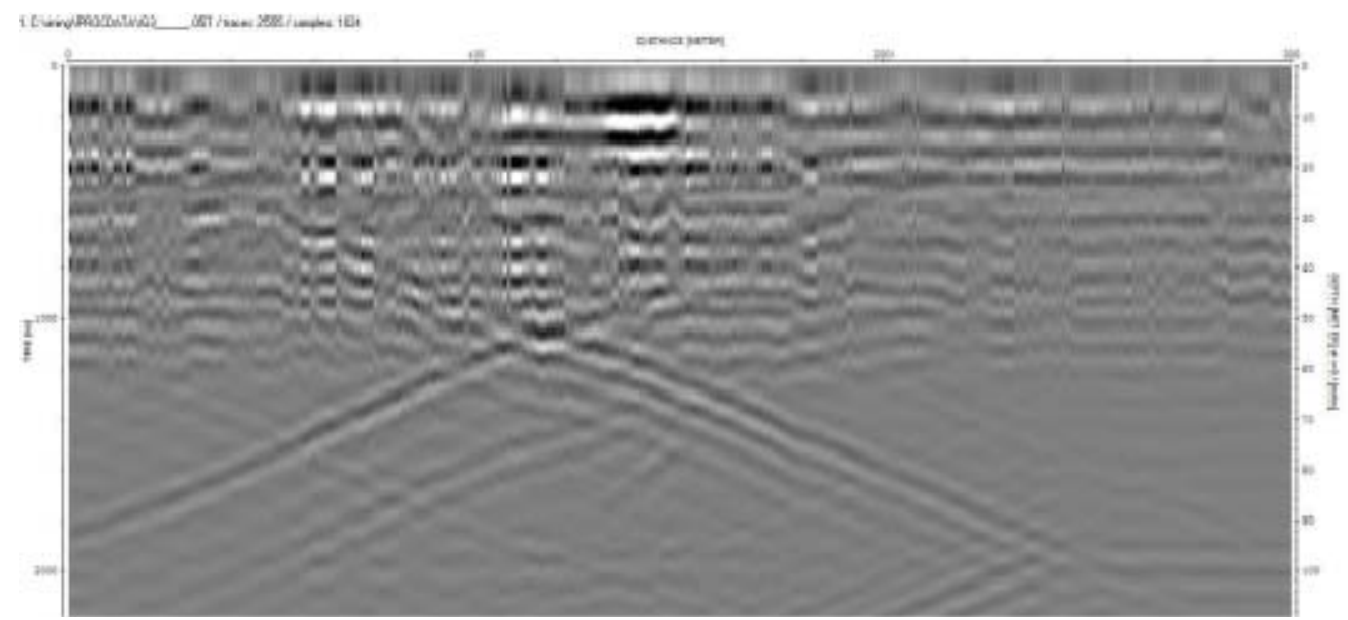

Figure 5 GV6 GPR gray scale at bottom slope of dam parallel to the dam axis

Found strong penetration band in dam bedrock. Through GV6 GPR test at bottom slope of dam that was parallel to the dam axis, found the bedrock under overburden exist significant strong penetration band in the range of $0+155$ to $0+205$, as shown in Figure 5 . 
Drilling holes at $0+160,0+180$ and $0+200$, fault fracture zone and partial unfilled fissure zone were seen. Self-water drilling emerged at the platform behind dam also proved that the monolith has strong permeability and a certain pressure resistance, as shown in Figure 6.

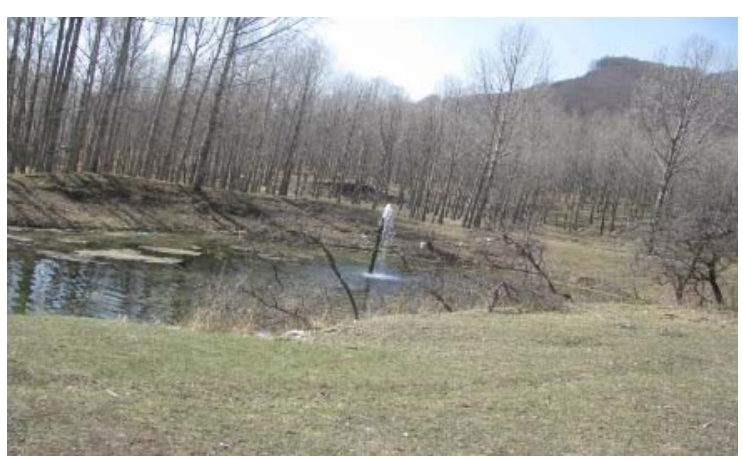

Figure 6 Self-water drilling at the platform behind dam

\section{Conclusions}

For a long time, the seepage problem of Nanmenxia Reservoir has not been able to solve. The important support was provided for the solution to the key problem by introducing British Groundvue radar equipment and software.

Through GV6 radar test and analysis, the position of dam foundation anti-seepage wall and the status of the extension were determined. According to the comprehensive analysis of multi-way measuring line of the front slope of dam, combined with the result of drilling core, the position of the seepage cut-off wall was $5.4 \mathrm{~m}$ away from the center line of upstream parkways curtain grouting to downstream bank. The thickness of the anti-seepage wall is about $0.50 \mathrm{~m}$, and it has the horizontal distance of about 3m away from the current grouting platform, which may be one important cause that the previous grouting effect was bad.

Found and determined that obvious strong permeability zone existed in the dam foundation rock by GV6 test and analysis, fracture zone could be seen in drilling verification holes at $0+160,0+180$ and $0+200$. Local part has no-fill fissure zone, which was the main leakage passage of deep dam foundation.

Through test and analysis by GV2 radar, there has obvious fissure zone in local of the right grouting tunnel to be found, which should be paid full attention in reinforcement.

\section{Acknowledgements}

This work was financially supported by the 948 Foundation of the Ministry of Water Resources (201325)

\section{References}

[1] Yang Wanke, Yang Yueju, Ma Shouzhong, Reasons analysis on Nanmenxia Reservoir seepage in Huzhu. J. Science and Technology of Qinghai Agriculture and Forestry, 18(2006)43-47.

[2] LI Y, CHEN J J C. Ground penetrating radar signal processing improves mapping accuracy of underground voids and seawater table: an application in deteriorating coastal structure, Nanfangao Port, Taiwan, J. Enviro- nmental Geology, 43(2007)35-39.

[3] Ma Huijie. Treat of the karsts and seepage for Nanmenxia Reservoir, J. Hydrogeology and Engineering Geology. 21(2002)43-48. 